\title{
Metodologia Cedet: caminhos para desenvolver potencial e talento
}

\author{
Zenita C. Guenther*
}

\begin{abstract}
Resumo
O presente artigo dá uma visão das dificuldades inerentes à área de pesquisa em educação especial para alunos dotados e talentosos, para introduzir a metodologia Caminhos para Desenvolver Potencial e Talento. Essa metodologia foi desenvolvida para a intervenção educacional nos Cedets (Centros para Desenvolvimento do Potencial e Talento), em cerca de vinte anos de estudos. O autor discute seu referencial teórico e ideário filosófico e apresenta uma orientação geral sobre a metodologia, com ênfase na dinâmica de construção e estabilizaçáo do ambiente educativo necessário ao processo de desenvolver capacidade humana. Termina com orientação para a organização do Plano Individual de Trabalho, elaborado semestralmente com cada aluno. Palavras-chave: Cedet, potencial, capacidade humana, dotação, ambiente educativo.
\end{abstract}

\section{The Cedet Methodology: ways of developing potential and talent}

\section{Abstract}

The article presents an overview of the difficulties faced by research on special education for gifted and talented students, when introducing the methodology of Ways of Developing Potential and Talent. This methodology was drawn up for educational intervention at the Cedets (Centers for the Development of Potential and Talent), after nearly twenty years of study. The author discusses its theoretical framework and philosophical ideal and presents general guidelines on the methodology, with emphasis on the dynamics for the building and stabilizing of the educational environment demanded for developing human capacity. It ends with guidelines on the organization of the Individual Work Plan, drawn up each semester with each individual student.

Keywords: Cedet, potential, human capacity, genius, educational environment.

\section{A Educação para Dotados e Talentosos destina-se a responder a} necessidades de desenvolvimento próprias a esse grupo específico de alunos.

* Ph.D. Cedet - Aspat (Centro para Desenvolvimento do Potencial e Talento - Associação de Pais e Amigos para Apoio ao Talento), em Lavras- MG. E-mail: zeguen@def.ufla.br. 
A intervenção educacional para alunos excepcionais, em qualquer excepcionalidade, alcança melhor seu objetivo quando focaliza o aluno, individualmente, testemunhando correlação entre o nível de conhecimento do educador e o sucesso da intervenção. Em uma palavra: o que se faz em educação para alunos dotados e talentosos é derivado do que se sabe sobre o tema. Para os programas de açáo educativa, esse tem sido um problema: sabe-se pouco, faz-se pouco; sabe-se mal, faz-se mal, pois o fazer reflete o saber, ou a falta dele.

\section{Por que inventar metodologia?}

Ao planejar o trabalho educacional do Cedet, visando desenvolver o potencial identificado nos escolares, foi necessário tomar decisóes sobre que caminho seguir para ter maior segurança de alcançar esse objetivo. Logo de início, esbarramos em questóes fundamentais que dificultam traçar planos efetivos para concretizar a intervenção educacional e, após paciente pesquisa, leitura, reflexão e análise do contexto de prática, algumas dificuldades principais foram localizadas.

\section{Distância entre a ciência e a prática educacional}

Existe conhecimento disponível na literatura internacional, o qual é frequentemente arejado em discussōes, debates, cursos, seminários, e publicaçóes. Mas esse saber permanece amplamente como um item decorativo, útil para exposiçóes, publicação, congressos, todavia sem chegar ao seu verdadeiro destino: os alunos identificados, ou que poderiam ser identificados pelo potencial que sinalizam. Por essa razáo, um dos primeiros objetivos abraçados pelo projeto pedagógico do Cedet envolve diminuir a distância entre o que se sabe e o que se faz em educação especial para alunos dotados e talentosos.

Assim, é uma preocupação permanente na metodologia do Cedet assimilar e ampliar continuamente o nível de conhecimento acumulado na área, para estabelecer conceituação clara, com base na pesquisa integrada de vários campos do saber, e caminhar na direção apontada por Gallagher (1997): levar o conhecimento sistematizado ao seu destino final, o aluno dotado e talentoso. 


\section{Obscuridade dos conceitos centrais}

Ao priorizar estudos teóricos limitados à leitura dos vários autores, a conceituação básica da área sugere o caos em ideias e termos, apontado por Gagné (2004). Numa visão medianamente aberta, verifica-se que a nebulosidade envolve utilizar palavras de uso comum num sentido vago para representar noçóes técnicas amplas e abstratas, sem diferenciar a que conceitos correspondem. Termos como dotação, capacidade elevada, talento, mesmo quando compreendidos e traduzidos corretamente, são de difícil transposição para a ação educativa.

Entretanto, a maioria das dúvidas poderia ser esclarecida pelo ideário teórico que diferencia capacidade natural de capacidade adquirida, sistematizado, por exemplo, em Angoff (1988), Plomin, (1998), Howe, Davidson e Sloboda (1998), consolidado no referencial organizado em Gagné (1999): Dotação refere-se ao potencial presente na constituição do indivíduo, indica alto grau de capacidade natural em algum domínio, originada por predisposição genética, desenvolvida com base em aprendizagem informal sedimentada, assegurando maior generalização e melhor previsão para aprendizagem futura. Talento, por sua vez, refere-se a desempenho superior, habilidade treinada, competência, expertise, que, mesmo alcançando altos níveis de produção, tem estreita área de transferência, privilegia experiência retrospectiva e evocação, com pouca previsão de aprendizagem futura.

Assim, desenvolver talentos pode ser um processo relativamente simples, que alcança resultados em menor tempo, e depende essencialmente de um plano pedagógico-educacional claro e determinado, focalizado em ensino, exercício, treino. Desenvolver dotação, isto é, o potencial sinalizado em um domínio de capacidade, é mais complexo, exige vivência em quantidade, qualidade, complexidade, profundidade, diversidade, por longos períodos de tempo, em condiçóes configuradas por vias de educação informal. Mas, considerando resultados em generalização e aprendizagem futura, desenvolver dotação é mais promissor para a pessoa, e para os objetivos da sociedade, que cultivar talentos. Sobre essa base foram definidos como objetivos do Cedet: desenvolver a dotação como identificada, e cultivar talentos, segundo oportunidades pontuais.

\section{Excessivo peso no domínio da inteligência}

Os conceitos, definiçôes e estudos na área de dotação permanecem centrados em manifestaçóes da inteligência, apesar da evidência empírica 
de que inteligência medida na infância não se relaciona com produção e sucesso alcançados na vida adulta, como assinalam autores como Freeman (2006) e Deary et al. (2004). Tal distorção conceitual pode ser captada, por exemplo, em definiçôes de criatividade, ou capacidade socioafetiva. Embora sejam primordialmente expressóes de capacidade para sentir, perceber, captar impressóes, esses domínios sáo definidos em alguns estudos em termos de funçôes intelectuais como pensar, compreender, relacionar. Perde-se de vista a ideia de que dotação implica alta capacidade localizada em um, ou mais, entre os diversos domínios de capacidade humana (GAGNÉ, 2009). Ainda mais, o potencial não se expressa por atributos e traços de personalidade, mas por meio de açóes, posicionamento e modo de aprender, captar e agir nas situaçóes encontradas. $\mathrm{O}$ professor que, na condução de sua prática, necessita descriçóes dinâmicas, e designs em redes que possam localizar sinais de capacidade nos vários domínios, depara-se com um quadro em que a maior parte dos estudos focaliza inteligência, medir desempenho ou explorar quantificação de atributos. Além disso, como aponta Feldhusen (2004), a maioria desses atributos devia ser visto como fins da educação para dotados, e não como meio de identificar potencial.

Portanto, era vital desenvolver para o Cedet uma metodologia que conduzisse à identificação de potencial nos diferentes domínios de dotação, sem se prender a listas de atributos, comportamentos e medidas de desempenho.

\section{Inutilidade do "enriquecimento"}

Em adição às dificuldades apontadas, o ponto crucial às decisões inerentes à configuração do trabalho do Cedet foi verificar: a) Os programas para alunos dotados são formatados como "atividades de enriquecimento". b) Mas o conhecimento acumulado pela pesquisa científica mostra que tais atividades não deixam resultados a longo prazo.

White (1992) certifica que, apesar da satisfação pessoal de alunos e professores, e alguma evidência de aprendizado localizado, as desejadas vantagens em termos de desenvolvimento do potencial desaparecem ao terminar a participação nos programas de enriquecimento. Subotnik et al. (1993) verificaram que 210 sujeitos selecionados na infância para uma escola especial em Nova York, apesar do intenso e longo programa de enriquecimento, nenhum havia alcançado projeção em qualquer área produtiva, na faixa de 
40/50 anos, nem eram mais bem-sucedidos que seus pares com QI e nível socioeconômico equivalentes. Holahan e Sears (1995) demonstraram que os históricos termites (sujeitos de Terman), selecionados na década de 1920 por QI, potencial em liderança, e criatividade, 75 anos mais tarde não haviam alcançado mais sucesso que um grupo de igual nível socioeconômico, recrutado ao acaso. Freeman (2006), em seu estudo com 70 crianças dotadas entre 5 e 14 anos, acompanhadas até a idade adulta, não conseguiu identificar fatores que influenciam no alcance de sucesso ou felicidade na vida, diferenciados das condições para autorrealização pessoal: compromisso, trabalho intenso, dedicação, suporte emocional na família, boa educação formal e oportunidades no ambiente, fatores amplamente conhecidos na orientação humanista, e que não dependem de programas de enriquecimento.

Em vista disso decidimos pensar para o Cedet um referencial metodológico diferente do referencial para atividades de enriquecimento, apesar de a palavra aparecer uma ou outra vez.

\section{O que faz diferença?}

Visto que conteúdo e desempenho específico não se transferem para outras situaçóes, e o efeito educativo de enriquecimento desaparece ao terminar o programa, o que faria efetivamente diferença no desenvolvimento do potencial? Para encaminhar essa questão, foram alinhadas algumas pistas:

a) Os processos que desenvolvem a dotação não podem ser ensinados, e são relativamente independentes de atividades, conteúdos, ou tipo específico de desempenho.

b) O desenvolvimento da dotação é influenciado pela maturação geral, o que leva tempo, e vivência quotidiana, condiçóes pouco previsíveis para fins de planejamento específico.

c) O caminho para desenvolver a dotação envolve tecer redes de aprendizagem espontânea, informal, não intencional, resistente a reforço e incentivos externos.

d) Aprendizagem informal caracteriza-se por ser uma teia assistemática de aquisiçóes adquiridas por experiência, frente às necessidades vividas, e oportunidades encontradas.

e) Sejam quais forem os valores aceitos, o crescimento da dotação acontece integrado à formação da pessoa: expansão da experiência de vida; 
convivência e identificação com pessoas "admiráveis"; presença de pares com interesse compatível. Tais fatores enraízam as aprendizagens internas de ser, desenvolvidas pela vivência de situaçóes diversificadas e esclarecimento dinâmico de valores pessoais e culturais.

\section{Aproximaçáo ao pensamento humanista}

Na sequência dessas aprendizagens, a metodologia do Cedet foi concebida com bases derivadas de pensadores humanistas, tais como Helena Antipoff, Paulo Freire, Abe Maslow, Art Combs. O pensamento humanista imprime direção ao projeto educativo pelas dimensôes da personalidade sadia: Eu (autoconceito realista e positivo), Outros (inter-relaçóes aceitáveis com os outros), Mundo (visão informada e realista do mundo), coerente com o conceito de Sabedoria, de Sternberg (2003): equilíbrio entre interesses intrapessoais, interesses interpessoais e aspectos do contexto no qual a pessoa vive, extrapessoais.

A aplicaçáo desses estudos ao ideário do Cedet levou à configuração do ambiente educativo, de Helena Antipoff, integrando elementos extraídos da pesquisa, a começar por Terman (1925), Honzik, Macfarlane e Allen (1967), à vasta literatura atual. Esses estudos apontam para apoio pessoal recebido na família e na escola, cuidado, afeição, preocupação sincera com a criança, como meios para promover melhoria significativa e duradoura, documentada tanto em termos de produção escolar, como na inteligência medida em QI.

\section{Ambiente educativo}

O ideário humanista e a resolução de servir ao sistema público direcionaram nossa atenção para crianças social e culturalmente desprivilegiadas, e aos estudos de Werner e Smith (1992) sobre resiliência. O termo resiliência, criado por esses autores, descreve uma força interior que permite às crianças sobreviverem, com suas qualidades, mesmo em condiçóes muito desfavoráveis, um fenômeno verificado especificamente em crianças pobres, dotadas de inteligência, em ambientes onde há apoio, respeito, interesse pessoal e sincero por parte dos adultos. Não por coincidência, esses princípios descrevem o ambiente educativo de Helena Antipoff: "Um ambiente 
propício para a Educação, no 'clima' mais favorável ao tipo de aluno [...]. Uma atmosfera de confiança e simpatia” (ANTIPOFF, 1992, p. 42).

No Cedet, o ambiente educativo é construído por uma rede de interaçóes mediadas pela equipe de especialistas, sobre quem repousa a responsabilidade na condução do processo educativo intencional. Tais princípios, buscados em Helena Antipoff, incluem os seguintes aspectos.

\section{Atitude científica}

Esse princípio coloca em perspectiva o empenho do Cedet em buscar conhecimento científico para basear o trabalho educacional, não somente analisando e absorvendo resultados de pesquisa, mas também incorporando, ampliando, em alguns casos modificando esses saberes, a partir da vivência educacional com as crianças, escolas, famílias, pessoas da comunidade.

Sem um complemento científico nosso trabalho seria restrito à mera repetição de técnicas, cujos resultados mal interpretados cairiam no natural desuso, ou se tornariam táo rotineiros e sem significação que nos aborreceriam com o seu peso morto e sua inutilidade. (ANTIPOFF, 1992, p. 11)

\section{Paciência, persistência}

Não é valioso para a educação ter pressa em concluir, achar resposta, criar modelo, pois uma resposta leva inevitavelmente a outra pergunta. Aprendizado é um processo, e como processo pode ter confiabilidade, validade e qualidade. Infelizmente, em meios educacionais parece haver pressão, tanto para introduzir e iniciar alguns planos, como para interromper e modificar outros, sem analisar devidamente os resultados.

\section{Quadro teórico em permanente construçáo}

Integrar conhecimento à ação educativa não permite a posição passiva embutida em adotar um ponto de vista, seguir um modelo, ou aplicar uma teoria. Quando a ação é iluminada por saber, cresce a necessidade de manter um quadro teórico em constante processo de construção, estudando, aprofundando, esclarecendo conceitos, incorporando ideias, reformulando afirmaçóes por ampliação do conhecimento e análise realista da prática. 


\section{Fé no conhecimento científico}

Conforme Antipoff (1992, p. 72), “[d]a ciência deve-se esperar a clareza na percepção da meta, dos objetivos, e do plano coordenado de açáo".

A relevância de bases científicas é uma dimensão sempre presente no arcabouço da metodologia do Cedet. Por exemplo, é com base em conhecimento científico que foi diferenciado o objetivo de desenvolver dotaçáo e capacidade natural, em preferência ao caminho mais direto de focalizar desempenho e cultivar talentos.

\section{Ênfase na imersáo ambiental}

O dia a dia imerso no ambiente educativo, intencionalmente cultivado, favorece captar a força da educação informal, liberada nas redes construídas pela convivência entre alunos, comunidade, professores, escolas, famílias, instrutores voluntários, estagiários, visitantes. Essa integração dá corpo, forma e conteúdo à concepção abstrata de comunidade educativa.

Para provocar crescimento do potencial e dotação, é necessário visualizar o processo educativo, conduzindo à formação da pessoa. Tal processo náo carrega conteúdo específico a ser ensinado, porque constitui um modo de ser vivido pela interação, identificação entre as pessoas, e exemplo absorvido na ação em comum. $\mathrm{O}$ que acontece de maneira natural, na vida em conjunto, tem direção intencional, mas não pode ser planejado previamente em nuances e detalhes. Esse tipo de educação abrange redes amplas e imprevisíveis de influência, veiculadas por meio de: expansão e diversificação da experiência de vida, presença de pares iguais e não iguais com interesses compatíveis, interação e convivência com personalidades admiráveis, aprendizagens internas de ser, clarificação de valores, e circunstâncias que interagem entre si na formação do ambiente educativo.

\section{Configura-se a metodologia}

A sigla Cedet, que designa o Centro Comunitário, refere-se também à metodologia desenvolvida para criar o ambiente específico de apoio, complementação e suplementação educacional ao aluno dotado e talentoso, matriculado em diferentes escolas e níveis de ensino. A metodologia Cedet 
(Caminhos para Desenvolver Potencial e Talento) implica em uma teia de conhecimento integrando estudos teóricos e prática registrada e analisada, vivida na comunidade educativa dos nossos Centros Comunitários (GUENTHER, 2011). O referencial básico apoia-se em dois conceitos: dotação (capacidade natural, aptidão, predisposição ou potencial presente no plano genético) e talento (indica capacidade adquirida, desempenho superior em um campo de atividade captado e expresso no ambiente).

\section{METODOLOGIA CEDET 2011}

(I)

Sistemas de Ensino
(Municipal - Estadual - Privado)
Equipe Central Diversificada
A m b i e n t e E d u c a t i vo

(II)

Desenv. Dotação

(Domínios)

Escolas

Alunos

F a mílias
$\mathrm{P}$

$\mathrm{L}$

A

$\mathrm{N}$

$\mathrm{O}$ Comunicação/Organização/Humanidades

I

$\mathrm{N}$ Investigação/Ciência/Tecnologias

D Expressão/autoconhecimento/Habilidades

I

$\mathrm{V}$

I

D

Instrutores Voluntários

$\mathrm{U}$

A Entidades Colaboradoras

(III)

\section{Processo educativo intencional}

$\mathrm{Eu}$ - Outro - Mundo

Densidade - Diversidade

Complexidade - Profundidade

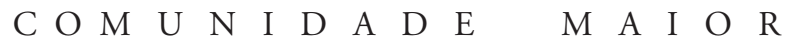




\section{Organizaçáo}

A parte superior do diagrama retrata a organização que antecede à dinamização da metodologia:

Sistemas de ensino

O ideal para um Centro Comunitário seria reunir os sistemas de ensino atuantes na comunidade, o que não só torna possível localizar a proporção de potencial humano existente, ainda na fase da infância e adolescência, como evita interrupçóes no processo por transferência do aluno de um sistema para outro, ou descontinuidade de níveis de ensino.

Equipe diversificada

Por ser um método apoiado na corresponsabilidade com as escolas, a equipe deve ser parte do quadro docente geral, em áreas diversificadas de formação. Tal medida assegura presença de profissionais de interesses diferentes na constituiçáo da equipe, o que leva à ampliaçáo da experiência educativa para as crianças.

Construção do ambiente educativo

Uma vez formada a equipe, sua tarefa é organizar o centro, de modo a criar a atmosfera necessária ao ambiente educativo, incluindo a integração das escolas, famílias e comunidade. A configuração do ambiente educativo deve contemplar as duas dimensóes diferenciadas pelos conceitos centrais: a) desenvolvimento da dotação pelo trabalho individualizado, amplamente informal, o que envolve a escola que a criança frequenta, a família com suas particularidades, e a ação do Cedet; b) desenvolvimento de desempenho, com foco no conhecimento, competência, habilidades e conteúdos específicos. O Plano Individual cimenta as duas dimensóes do processo educativo para cada aluno, compatibiliza sua realidade pessoal com o potencial identificado, a partir das necessidades e interesses captados pelo facilitador nos diferentes momentos e fases do crescimento do aluno.

\section{A intervenção}

Desenvolvendo dotação

Domínios: ao lado esquerdo do diagrama, alinham-se os elementos básicos ao processo de desenvolver a dotação, sendo o primeiro a identificação dos domínios de capacidade. 
Escolas: o primeiro interlocutor do Cedet é a escola. A criança "pertence" à escola e, em razão de sua capacidade muito acima do grupo de pares, recebe no Cedet o apoio suplementar necessário ao seu desenvolvimento. $\mathrm{O}$ facilitador traça seu mapa de trabalho com base nas escolas que lhe cabe orientar: conduz a coleta de dados de observação, ponto inicial da identificação, que constitui a maior referência para o projeto educativo da criança; vai à escola todas as semanas para trabalhar com seu aluno, configurar o Plano Individual, acompanhar o desenrolar do plano durante o semestre, conversar, interagir, aconselhar, ajudar a estruturar a maneira como o aluno desenvolve seu projeto de vida em casa, na comunidade, na escola e no próprio centro.

Alunos: obviamente, o aluno é o centro nevrálgico da metodologia. Tudo acontece a partir de sua pessoa, sua capacidade, sua história de vida, seus interesses, seu cotidiano e momento atual, com vistas a encaminhar seu projeto de vida a longo prazo. O registro básico do processo educativo centra-se no aluno: a) a ficha acumulativa, onde tudo é anotado à medida que vai acontecendo, no decorrer do tempo; b) o plano individual, que dá sentido e ordem ao viver do dia a dia, e da semana, colocando em perspectiva o trabalho no Cedet integrado ao semestre da vida regular na escola.

Famílias: em princípio, toda criança é social e emocionalmente dependente dos adultos responsáveis por sua existência, sua educação, manutenção física, psicológica e social, especificamente durante o período de crescimento e formação. Antes de ser "da escola", a criança é "da família". No Cedet, a família é a segunda instância na tomada de decisóes sobre a criança. Embora o processo de educar seja uma vivência pessoal, é o contexto familiar que confere os contornos, limites e extensão das expectativas que uma criança traz para o dia a dia na escola. No Cedet, portanto, a família é integrada diretamente a partir do arcabouço escolar, e indiretamente por meio da Aspat (Associação de Pais e Amigos para Apoio ao Talento).

\section{Plano Individual}

Ao centro da figura, em vertical, desenha -se o Plano Individual do aluno, como uma ponte, unindo: de um lado, o esforço direcionado para desenvolver sua dotação, um evento interno, pessoal, apoiado no domínio de capacidade previsto pela sua constituição genética; de outro, as açóes educativas do viver concreto e público da criança, seus afazeres, atividades, conteúdo estudado, enfim, o processo de instalar e aperfeiçoar desempenho. 
Desenvolvendo o desempenho

Competências: à direita do gráfico, alinham-se elementos relativos aos objetivos de curto e médio prazo, na área onde podem se revelar os talentos, por focalizar conhecimento, desempenho, habilidades, expertise. Essa é a dimensão da metodologia que lida com ensino de conteúdos, manejo de informaçóes, instalação e treino de competências nos vários campos (GROSS, 1993).

Áreas pedagógicas: são locais que abrigam os professores que constituem a equipe, de acordo com a formação, interesse e experiência profissional. A subdivisão de conteúdos em áreas inspira-se também no referencial humanista - eu, com o outro, com o mundo.

Comunicação/Organização/Humanidades: focaliza interaçôes interpessoais, vida social, e inter-relaçóes humanas, levando ao reconhecimento e concepção do Outro. Como campo de estudo, engloba experiências e temas em organização geográfica, histórica e social, aprendizado de línguas, comunicação e mídia, intercâmbios culturais, vivência em comum com grupos diversificados de pessoas, crianças, jovens, adultos.

Investigação/Ciência/Tecnologias: explora o contexto no qual vivemos, com vistas à formaçáo da visão de mundo; abre portas para o conhecimento científico, pela aquisição de instrumental e métodos empregados pela ciência para abordar, compreender e pensar o mundo; busca informar, situar, preservar, influir e modificar o contexto do mundo onde vivemos.

Expressão/Autoconhecimento/Habilidades: sonda a esfera pessoal de vivência interna, promove autoconhecimento e formação pessoal pela exploração dos próprios sentimentos, apreciação da beleza, experiência no cultivo das artes, compreensão e expressão do corpo, aperfeiçoamento de habilidades pessoais, autocontrole e autorregulação.

Instrutores voluntários: os instrutores voluntários são recrutados na comunidade para conduzir exploração dos conteúdos específicos, desenvolvidos em atividades individuais e grupais. A presença de voluntários no Cedet náo é medida de economia, mas de qualidade para o projeto pedagógico, por dominarem os assuntos de interesse das crianças, ao nível de profundidade e complexidade necessária ao aluno mais capaz e por isso mais exigente.

Como base do recrutamento de instrutores voluntários estão estudos teóricos, de Helena Antipoff, no Brasil, a Larissa Shavinina (2004), 
no Canadá, mostrando que um fator de maior alcance no desenvolvimento da capacidade natural é inspiração, exemplo, contato e convivência com pessoas admiráveis, ativas, produtivas, bem formadas, respeitadas na comunidade.

Entidades colaboradoras: são entidades públicas e privadas existentes na comunidade, chamadas a colaborar com o programa educativo, especificamente na exploraçáo de conteúdos, tanto disponibilizando profissionais para atuar como instrutores voluntários, como provendo espaço, equipamentos e ambientes apropriados, tais como laboratórios, oficinas, praças de esportes.

\section{O contexto}

Na base do diagrama está a contextualização do trabalho e integração do processo pedagógico, como um processo educativo intencional. As dimensões eu - outro - mundo, elementos básicos à formação humanista, constituem o horizonte para o qual se dirige o caminho para desenvolver a dotação. No campo do desempenho e competência, alinham-se marcas do processo pedagógico, visto como um esforço de ensino: densidade - diversidade - complexidade - profundidade.

Nenhuma metodologia educativa pode ter sucesso se alienada da comunidade a que serve, onde são desenhados os contornos do dia a dia. Assim, a metodologia do Cedet foi criada tendo em mente firmar raízes na comunidade, como base e cenário para seus objetivos, de modo que a comunidade maior situa a metodologia em sua área concreta de açáo. Formada pelo conjunto de famílias e entidades diversas, a comunidade é o contexto a partir do qual a criança vem para a escola, e para onde volta ao terminar a escolarização. Portanto, embora educação esteja na base da construção do projeto de vida, o cenário onde tal projeto se configura é a comunidade, em seus variados contornos e extensão.

\section{Intervençáo educativa}

Desenvolver talentos focaliza almejar e cultivar altos níveis de desempenho por meio de ensino, instrução, exercício e prática. Para que tais padrões sejam alcançados, são necessárias certas condiçóes inerentes ao indivíduo, além de capacidade e dotação, tais como empenho, desejo de 
se desenvolver e disponibilidade interior para buscar e receber ensino. É também necessário aplicar disciplina, dedicação e esforço, que asseguram melhoria progressiva da qualidade. Já os fatores que desenvolvem a capacidade natural não são ensinados e agem por meio de vias processuais não diretamente planejáveis: amadurecimento e maturação geral do organismo, aprendizagem espontânea, informal, assistemática, processada pela vivência cotidiana, experiência de vida, convivência, oportunidades, possibilidades encontradas, e circunstâncias do acaso.

Pessoas que influíram no cenário geral da humanidade efetivamente apontam contingências da vida e fatos ao acaso como fatores que contribuíram para seu desenvolvimento (SHAVININA, 2004). No Cedet, tentamos encontrar meios para bater o acaso e vencer contingências da vida para os alunos dotados, mesmo vivendo em ambientes adversos. $\mathrm{O}$ acervo de pesquisa científica sobre desenvolvimento de capacidade humana tem comprovado a força educativa dos seguintes fatores.

\section{Experiência vivida}

O viver uma situação relacionada a uma necessidade percebida, expressa pelo interesse, torna a pessoa mais experiente. Uma vez que desenvolver dotaçáo independe de ensino específico, ao planejar uma atividade de conteúdo é necessário assegurar que: a) o aluno de fato tem interesse; e b) há na situação uma vivência concreta. Falar, ouvir, discutir, debater, ler, ver filmes, escrever resumos não amplia experiência de vida. Ainda mais, a influência do fazer não está na atividade em si, mas na incorporação da experiência vivida. Entretanto, existem alguns tipos de vivência que parecem constituir necessidades comuns ao ser humano, principalmente em fase de desenvolvimento, e podem ajudar a compor um plano de intervenção educativa:

a) Viver experiências novas, experimentar o que nunca viveu antes.

b) Alcançar sucesso, reconhecer e sentir o próprio valor pessoal.

c) Conviver com pares, para observar reaçóes, novas expressóes, e aprender por imitação.

d) Interagir com não iguais, para compreender e captar maneiras diferentes de ser.

e) Enfrentar diversidade de situações para observação de detalhes e novas relaçóes. 


\section{O fator tempo}

O tempo necessário para provocar desenvolvimento do potencial, por meio de planos de intervenção educativa, fica ao redor de 8 a10 horas semanais, a curto prazo, o que possibilita intensidade na intervenção. A médio prazo, exige 4 a 5 anos consecutivos, permitindo adicionar diversidade, profundidade e complexidade às situaçóes vividas. A longo prazo, o processo continua pela vida, refletido em produção e sucesso alcançado. Mas passar o tempo não basta: é imprescindível que esse tempo seja marcado por "viver" algo associado a um objetivo abraçado. $\mathrm{O}$ sucesso ou fracasso em alcançar o objetivo leva a aprender pela vivência.

\section{Rede de educaçáo informal}

Educação informal influi no acervo de experiência de vida porque compreende aprender pelo viver e conviver, no encaminhamento das necessidades do dia a dia. Intervenção educativa consiste em prover oportunidades para o educando enfrentar e viver situaçôes diferenciadas, facilitar, abrir portas, ajudar, sem ignorar o acaso, e sem contar com ele.

A rede de educação informal exerce influência direta e indireta no desenvolvimento do aluno, tanto pelo que acontece, como pelas interações e apoio que suscita. Essa rede é tecida a partir do modo de ser e viver da criança nas várias esferas, incluindo o que vive na escola, sua posição, interesse, ação e envolvimento na vida em família, e em tempo na comunidade. No Cedet, a influência estrutura-se, principalmente, pelo vínculo formado com o facilitador que orienta o projeto educativo individual.

\section{Aprendizagem sedimentada}

O acervo de aprendizagem sedimentada resulta da realização concreta, responsável e refletida do que é assentado no Plano Individual, incluindo os assuntos estudados, informaçóes e habilidades adquiridas. Relaciona-se ao nível de densidade da aprendizagem, computado pelas horas trabalhadas na semana. É influenciado pelo grau de diversidade das situaçóes e vivências, principalmente por experiências vividas no âmbito das áreas de estimulação, 
e pelo grau de complexidade e profundidade das aprendizagens, situaçóes e conteúdos desenvolvidos, em cada atividade realizada.

Com objetivo de assegurar validade na aprendizagem sedimentada, a intervenção educativa tem necessariamente que ser calibrada pelo que o aluno vai viver, e não pelo conteúdo a ser ensinado: a) enriquecimento envolve explorar, manejar, experimentar com temas estudados, em busca de novas ideias; b) aprofundamento exige viver situaçóes que ampliam em várias direçóes o nível de conhecimento adquirido; c) novidade envolve lidar com situações, temas e assuntos não explorados.

\section{Crescimento pessoal} derando:

O crescimento pessoal é abordado pela vivência de situaçóes, consi-

a) relevância pessoal e social, experiências e situações de efetiva importância e valor para o próprio aluno, para os outros, e para o mundo;

b) convivência com pessoas "admiráveis", para esclarecer direçóes ao projeto de vida;

c) interação com pares compatíveis, para amenizar a sensação de ser diferente;

d) aprendizagens de ser, esclarecendo o que é relevante ao meio onde vivemos, pelo exemplo observado, convivência, açôes e reaçôes compartilhadas na vida em comum.

\section{O Plano Individual}

O Plano Individual tem se mostrado absolutamente positivo como estratégia para organizar a intervenção, de modo que cada criança receba o que realmente precisa, e que responde aos seus interesses e necessidades, a curto e longo prazo. Slavin (1996), no seu projeto Sucesso para todos, indica o Plano Individual como a melhor forma de trabalhar com crianças desatentas e agitadas, com dificuldades de aprendizagem, ou em risco de fracasso escolar. O mesmo caminho mostrou-se valioso para alunos dotados, especialmente em um centro comunitário agregando várias escolas, com crianças de várias idades, características, interesses e tipos diversificados de capacidade e talentos (FELDHUSEN, 1995). 
No Cedet, o Plano Individual é, em essência, um projeto semestral de trabalho, feito pela criança junto ao seu facilitador, orientado pelo domínio de capacidade identificado no aluno, e dosado de acordo com suas peculiaridades, nível de maturidade, estilo e ritmo de aprendizagem, interesses atuais, preferências, necessidades e condições de vida pessoal. $\mathrm{O}$ plano individual é dinamizado pela combinação de variadas experiências, vivências, atividades individuais e grupais, imersão no ambiente educativo, com acompanhamento e orientação pessoal.

\section{Elaborando o plano semestral}

Para a composição de um Plano Individual, o primeiro passo é conhecer o(s) domínio(s) em que o aluno sinaliza ter capacidade natural, e que expressóes dessa capacidade foram observadas. A atenção deve estar concentrada no domínio, ou domínios sinalizados pelo processo de identificação, acrescidos de dados coletados durante o período de convivência e trabalho com a criança. Para tal, os facilitadores frequentemente precisam rever o referencial e fundamentaçáo teórica da metodologia, pois sua atuação junto ao aluno tem que estar clara, exigindo que saiba exatamente por que está tomando uma posição, e não outra, com aquele aluno, mas não com outros.

Para desenvolver dotação, um conceito quantitativo referente à presença de elevada capacidade, o processo segue a via da educação informal, por isso não importa que atividade ou conteúdo é desenvolvido, ou nível de desempenho alcançado. Educaçáo informal implica em encontrar no dia a dia, ao viver e conviver, situaçóes concretas de aprendizagem marcadas por densidade, diversidade, dificuldade e profundidade.

Os catalisadores intrapessoais e ambientais estabelecem um núcleo de diferenças e condiçôes individuais (GAGNÉ, 2009; GAGNÉ e GUENTHER, 2010), portanto, são pontos de apoio para um plano individual. A análise dos vários catalisadores atuando no dia a dia da criança traz elementos úteis ao planejar, realizar, avaliar e chegar a uma conclusão no processo de aprender por vias informais. Tais catalisadores incluem: consciência das próprias forças e fraquezas, da capacidade específica e qualidades intrapessoais; dos valores e necessidades, direcionando a escolha de objetivos apropriados ao desenvolvimento; e, finalmente, dos interesses imediatos, que levam a planejar as açóes, experiências e situaçóes concretas que configuram o dia a dia de trabalho para o aluno. 
Para dar fundo ao plano individual, é necessário estudar a situação da criança na família e na escola, estendendo para o bairro, vizinhança, comunidade maior. Conhecer o meio em que o aluno vive ajuda a tornar o planejamento concreto, possível e viável, para ele. Segue-se uma análise da influência das pessoas significantes atuando junto ao aluno, da importância que essas pessoas dão à sua educação, o apoio recebido pela criança, e o grau de saúde psicológica no lar e na sala de aula. O impacto de influências interpessoais é mais fácil de se imaginar do que outras fontes de influência, mas aumentar indevidamente a importância das pessoas não tem qualquer validade quando essa não for real, ou não tiver significação pessoal na vida do aluno.

A elaboração do plano acontece ao início de cada semestre (GUENTHER, 2008), começando por analisar com a criança o que ela viveu no semestre anterior, se chegou ao final esperado e se sente que foi proveitoso e satisfatório, o que ficou inacabado e deveria ser continuado, o que deixou de fazer, mas vale a pena tentar recomeçar, enfim, uma avaliaçáo em profundidade da experiência vivida pelo aluno no período anterior, em casa, na escola, no Cedet e na vida na comunidade.

Durante essa conversa, o facilitador tem oportunidade de expressar seu ponto de vista, trazer dados concretos, emitir sua própria avaliação, dentro do clima de confiança que se estabelece na convivência entre ele e seu aluno. Quando o aluno é novato no Centro, essa conversa ajuda a conhecer melhor a criança, suas preferências, interesses, desconfianças, de modo a chegarem juntos a um acordo sobre o que planejar, com probabilidade de cumprir o plano feito. Esses dados são registrados na Ficha Individual, que acompanha o aluno durante todo o seu tempo no Cedet.

Segue-se a exploração de outros ângulos do projeto educativo, inerentes ao momento atual:

\section{Interesses e preferências}

Sem dúvida um bom plano educativo deve ser apoiado em vivências agradáveis, sem ser necessariamente um momento lúdico, ou de simples lazer. Ao se pensar o plano há oportunidade de discutir com a criança o que ela faz com prazer, gosta, aprecia, e está motivada a continuar cultivando, mesmo que esteja nessa atividade há um ou mais semestres. São anotados também novos assuntos, curiosidades, prontidão tentar, explorar, experimentar com áreas que ainda não viveu, sejam ou não parte da vida escolar. O referencial primordial é o domínio de capacidade, acoplada à 
faixa etária atual, pois ali devem estar pontos de referência ao se estabelecer o que se pode tentar com probabilidade de sucesso, na direção em que deve caminhar o processo de desenvolver do seu potencial. Essa parte do plano assegura dedicação e gosto do aluno pelo que vai fazer durante o semestre, e ajuda a manter motivação e freqüência às açóes planejadas.

Necessidades observáveis

Outro eixo do Plano olha em direção a situaçóes que o aluno deve ser orientado a enfrentar, em razão de haver alguma coisa a aprender, melhorar ou corrigir. Nesse momento, a criança é guiada a sondar áreas a que deveria dedicar algum tempo e esforço, como investimento de base em seu desenvolvimento geral. Pode ser, por exemplo, estudar uma disciplina da escola em que precisa construir base mais sólida, ou fazer uma leitura aconselhada na preparação para um projeto futuro.

Autogestão pessoal

Como fechamento do plano, pode-se pensar em um bloco opcional de objetivos, que consiste em levar o aluno a focalizar aspectos de si próprio, em termos de qualidades pessoais que gostaria de desenvolver ou aperfeiçoar. Tais objetivos podem abranger qualquer área, por exemplo, parar de discutir em casa, organizar melhor os horários de estudo, ser mais pontual, cumprir os compromissos assumidos. O papel do facilitador é claramente o do conselheiro, guiando a criança em uma autoanálise sincera e definição de objetivos exequíveis.

A elaboração do Plano Individual segue etapas sequenciais, com o tempo necessário diferenciado para cada aluno. Há crianças que demoram mais em uma ou outra etapa. Como princípio geral, o período de elaboração do plano individual, para a maioria dos alunos, não deve se alongar mais que duas a três semanas.

\section{Avaliaçáo, preparação e sondagem}

Primeira etapa, iniciada pela avaliação do período anterior vivido pelo aluno, vai se completando na medida em que se configura um levantamento geral, mesmo que desordenado, sobre os compromissos, ideias e interesses que haviam sido anteriormente arejados. $\mathrm{O}$ facilitador estuda com o aluno a possibilidade de incorporar ao plano atual as ideias e temas lembrados ou discutidos, mas não efetivados no passado. 
O objetivo final é compor uma lista das possíveis experiências e conteúdos a serem incorporados ao plano do semestre. Feito um traçado geral, procede-se a uma apreciação das possibilidades do aluno para execução desse plano e previsão de problemas que possam aparecer. São levantadas questóes relativas à concretização do que está sendo planejado e compatibilidade das atividades pensadas com o tempo de que ele dispóe na semana, uma vez bloqueados os espaços para: aulas e trabalhos escolares; tempo ocupado por outros afazeres; e o dia para a reunião com o facilitador. Esse estudo mostra ao aluno os horários e espaços que ele pode alocar ao trabalho no Cedet.

\section{Organização geral}

Em seguida, os facilitadores reúnem-se em equipe, estudam o material colhido com cada um dos alunos, buscando visualizar não só experiências de aprendizagem, mas também a estrutura básica de horários, locais e instrutores necessários à organização do trabalho semestral no Centro. O primeiro nível de ação implica a integração, pela equipe, do material de cada facilitador, em cada turno de cada escola e em cada turno por interesse dos alunos, ou seja: que alunos indicam que temas para estudo; que alunos devem ser integrados em uma atividade de grupo; que alunos devem ser orientados para situaçóes individuais.

O período de organização não pode ser longo, para não atrasar o início do trabalho, mas leva algum tempo, pois, após esquematizado, a maior parte das atividades grupais deve estar razoavelmente configurada e as atividades individuais, colocadas em perspectiva de ação. Feita a listagem das atividades grupais, as áreas decidem que atividades devem ser desenvolvidas, em que períodos e dias da semana. Nesse momento, são contatados os possíveis instrutores voluntários, sondadas as situaçóes de instalação de atividades dentro do âmbito escolar, ou na comunidade, e delineado o plano geral para atividades grupais e individuais. Os instrutores voluntários ajudam nas decisóes relativas ao dia, horário e local onde cada grupo deve se encontrar durante o semestre, ficando cada facilitador responsável por agilizar as atividades individuais de seus próprios alunos. $\mathrm{O}$ conteúdo e experiências a serem desenvolvidos correspondem a assunto a ser assentado entre o instrutor da atividade e a criança, ou grupo de crianças que desejam explorar aquele tema. 


\section{Fechamento e completaçáo}

Quando o plano geral está completo, o facilitador volta a falar com seus alunos individualmente, com essas informaçóes em mão, para o fechamento do plano e formalização do compromisso de trabalho para o semestre. Modificaçóes de temas, horários, e planejamento grupal ou individual, e detalhes da dinamização do trabalho, tudo deve ser pensado e configurado durante esse tempo, nesse espaço de duas a três semanas, ao início de cada semestre.

Quando o plano estiver pronto e aprovado por todos os envolvidos, ele deve ser cumprido até o final do semestre, sem modificações, a não ser em situaçōes muito específicas. Portanto, nesse momento, é definido o que vai ser realizado, em grupo e individualmente, e o aluno assume a responsabilidade de cumprir o acordado. A partir desse dia, não se modifica mais o planejamento, o qual deve ser cumprido e acompanhado até o final do semestre, quando se faz a avaliação geral.

Por esse planejamento conjunto, no qual o aluno tem autonomia para tomar decisão e assume a responsabilidade por sua escolha, espera-se uma vivência que o ajude a desenvolver senso de planejamento, a pensar com antecedência sobre o que deseja realizar, incluindo trocas de impressōes com colegas, familiares e professores. Mas, principalmente, que se empenhe em cumprir o compromisso assumido até o final do semestre, conforme é discutido e assentado.

\section{Documentaçáo e registros}

Para um trabalho com base na ciência da educação, há que haver registros, pois, como afirma Helena Antipoff (1992), ciência se faz com registros. Por essa razáo, o processo e avaliaçáo contínua do que acontece no Cedet, seja pelos facilitadores, seja pelo aluno, tudo é cuidadosamente registrado. $\mathrm{O}$ acervo de registros acumula-se por meio de um plano em espiral, com momentos de reflexão nas sessōes semanais da equipe e pelo menos duas instâncias de avaliação sistematizada, a cada final e início de semestre letivo. Os registros regulares incluem:

Registros do aluno

Ficha acumulativa (única); plano individual de trabalho (um por semestre); atividades individuais. 
Registros das áreas pedagógicas

Folhas de frequência relativas às atividades grupais; relatório semestral do andamento de cada atividade realizada; banco de ideias e sugestóes; cadastro de voluntários.

\section{Registros do Centro}

Documentos oficiais de secretaria; caderno dos encontros gerais; escrituração escolar regular: atas, relatórios, atestados, declaraçôes, correspondências; cadastro e contratos dos instrutores voluntários.

\section{A pasta da escola}

Os registros de manuseio constante são organizados e mantidos em uma pasta organizada para cada escola, onde são coletados:

1. folhas de observação para dados de identificação, referentes ao ano anterior e atual;

2. alunos sinalizados por conselhos de classe;

3. lista dos alunos inscritos;

4. lista de alunos em observação assistida;

5. dados do assistente interno da escola;

6. cópia do acordo assinado pela escola (se houver);

7. correspondência enviada e recebida (daquela escola);

8. ficha individual acumulativa dos alunos;

9. Plano Individual dos alunos, referentes ao ano em curso;

10. síntese da atenção dispensada a cada aluno.

\section{Síntese}

Ao final de cada semestre, uma folha de síntese registra a avaliação da experiência vivida pela criança naquele período, feita a partir do Plano Individual. Esse é um dos registros documentais mais importantes na metodologia do Cedet, por seu potencial para validação científica do processo educativo desenvolvido com cada criança, em cada escola, a cada ano.

\section{Alertando}

No DMGT, Gagné (2004) define como população geral de dotados os mais altos $10 \%$ da população, em cada faixa etária, alargando 
a faixa da probabilidade que prevê os 3 a $5 \%$ localizados a dois desvios padróes acima da média, nos diferentes domínios. Assim, a prevalência de excepcionalmente dotados, dentro da populaçáo de dotados, chega a cerca de 1:1. 000 na população normal. Pela nossa metodologia de identificação, isso corresponde a um aluno em cada grupo de 30 a 40 alunos identificados e inscritos no Cedet.

Dotação excepcional é um fenômeno raro, como já dizia Helena Antipoff (1992). Se pensarmos em dotação imaginando alguém com extrema capacidade, teremos uma imagem distorcida do que crianças dotadas são, na realidade. E se apresentarmos dotação e talento como um fenômeno muito excepcional, isso pode induzir os administradores dos sistemas a julgar que uma população assim tão rara não exige grande investimento de tempo e dinheiro para suas necessidades especiais.

Desse modo, também precisamos lembrar que, provavelmente, só uma fração das crianças dotadas ou talentosas identificadas na idade escolar chega a atingir altos padróes de excelência na vida adulta. Mas 1 em cada grupo de 30 a 40 de nossos alunos deve chegar a esse nível. Portanto, não vamos desanimar, mas também não vamos estabelecer objetivos demasiadamente, nem para nós e nem para eles.

\section{Referências}

ANGOFF, W. H. The Nature-Nurture Debate, Aptitudes, and Group Differences, 1. American Psychologist, v. 43, n. 9, 7 13-720, 1988.

ANTIPOFF, H. A Educação do Bem Dotado. Coletânea de Escritos de Helena Antipoff, v. 5, SENAI-RJ, 1992.

DEARY, I.; WHITEMAN, M.; STARR, J.; WHALLEY, L.\& FOX, H. The impact of childhood intelligence on later life. Journal of Personality and Social Psychology, 86, 130-147, 2004.

FELDHUSEN, J. Talent Identification and Development in Education (Tide). Center for Creative Learning Inc., 1995.

. Transforming gifts into talent: a response. High Ability Studies, 15,150-152, 2004. 
FREEMAN, J. Giftedness in the Long Term. Journal for the Education of the Gifted, 29, 384-403, 2006.

GAGNÉ, F. My convictions about the nature of human abilities, gifts and talents. Jo. for Educ of Gifted, 22, 109-36, 1999.

. Transforming Gifts into Talents: The DMGT as a Developmental Theory. High Ability Studies, 15, 119-147, 2004.

. Building gifts into talents: Detailed overview of the DMGT 2.0. In: B. MacFarlane, \& T. Stambaugh, (Eds.). Leading change in gifted education: The festschrift of Dr. Joyce VanTassel-Baska. Waco, TX: Prufrock Press, 2009.

. GUENTHER, Z. C. O DMGT 2.0 de Françoys Gagné: Construindo talentos a partir da dotação. Sobredotação, ANEIS, Portugal, n. 11, p. 7-23, 2010.

GALLAGHER, J. Least Restrictive Environment and Gifted Education. Peabody Journal of Education, 72 (3 e 4), p. 153-165. 1997.

GROSS, M. U. M. Nurturing the talents of exceptionally gifted individuals, International Handbook of Giftedness and Talent. Oxford: Pergamon Press, 1993.

GUENTHER, Z. C. CEDET 15 anos “Coleção Debutante”, ASPAT UFLA - FAEPE, Lavras MG, v. 3 Metodologia, 2008.

- Caminhos para Desenvolver Potencial e Talento. Coletânea Maioridade. Lavras-MG: Editora UFLA, 2011.

HOLAHAN, C. SEARS, R. The Gifted Group in Later Maturity. Stanford, CA: Uni. Press, 1995.

HONZIK, M., MACFARLANE, J., ALLEN, L. 1948. The Berkeley Guidance Study, Journal of Experimental Education; HONZIK follow up The Berkeley Guidance Study Berkeley Ca. 1967.

HOWE, M.; DAVIDSON, J.; SLOBODA, J. Innate talents: Reality or myth? Behavioral and Brain Sciences, v. 21, p. 399-442, 1998. 
PLOMIN, R. Genetic influence and cognitive abilities. Behavioral and Brain Sciences, v. 21, n. 3, p. 420-21, 1998.

SHAVININA, L. Explaining High Abilities of Nobel Laureates. High Ability Studies, 15, 2, 243-254, 2004.

SLAVIN, R. E. Every Child, Every School-Success for all. California: Corwin Press Inc., 1996.

STERNBERG, R. WICS as a Model of Giftedness. High Ability Studies, v. 14, n. 2, p. 109-37, 2003.

SUBOTNIK, R., KASSAN, L, SUMMERS, E. \& WASSER, A. Genius Revisited: High IQ Children Grow Up. New Jersey: Ablex, 1993.

TERMAN, L. M. Genetic studies of genius: Mental and physical traits of a thousand Gifted children. v. 1. Stanford, CA: Stanford University Press, 1925.

WERNER, E.; SMITH, R. Overcoming the Odds: High Risk Children from Birth to Adulthood. Cornell: Cornell University Press, 1992.

WHITE, K.R. The relation between socio-economic status and academic achievement. Psychological Bulletin, 91, 461-481, 1992.

Recebido em: 30 nov. 2011.

Aceito em: 29 jan. 2012. 